\title{
An evaluation of additives for mitigating the risk of virus-contaminated feed using an ice block challenge model
}

\author{
Scott Dee ${ }^{1}$, Roy Edler ${ }^{2}$, Dan Hanson ${ }^{1}$, Aaron Singrey $^{2}$, Roger Cochrane ${ }^{3}$, Megan \\ Niederwerder ${ }^{4}$, Gordon Spronk ${ }^{2}$, and Eric Nelson ${ }^{5}$ \\ ${ }^{1}$ Pipestone Veterinary Services \\ ${ }^{2}$ Affiliation not available \\ ${ }^{3}$ Pipestone Veterinary Sevices \\ ${ }^{4}$ Kansas State University \\ ${ }^{5}$ South Dakota University
}

May 12, 2020

\begin{abstract}
The role of animal feed as a vehicle for the transport and transmission of viral diseases was first identified during the porcine epidemic diarrhea virus (PEDV) epidemic in North America. Since that time, various feed additives have been evaluated at the laboratory level to measure their effect on viral viability and infectivity in contaminated feed using bioassay piglet models. While a valid first step, the conditions of these studies were not representative of commercial swine production. Therefore, the purpose of this study was to evaluate the ability of feed additives to mitigate the risk of virus-contaminated feed using a model based on real-world conditions. This new model used an "ice-block" challenge, containing equal concentrations of porcine reproductive and respiratory syndrome virus (PRRSV), Seneca-virus A (SVA) and PEDV, larger populations of pigs, representative commercial facilities and environments, along with realistic volumes of complete feed supplemented with selected additives. Following supplementation, the ice block was manually dropped into designated feed bins and pigs consumed feed by natural feeding behavior. After challenge, samples were collected at the pen level (feed troughs, oral fluids) and at the animal level (clinical signs, viral infection, growth rate, and mortality) across five independent experiments involving 15 additives. In 14 of the additives tested, pigs on supplemented diets had significantly greater average daily gain (ADG), significantly lower clinical signs and infection levels, and numerically lower mortality rates compared to non-supplemented controls. In conclusion, the majority of the additives evaluated mitigated the effects of PRRSV 174, PEDV, and SVA in contaminated feed, resulting in improved health and performance.
\end{abstract}

\section{Hosted file}

Dee S, Feed mitigation main document.docx available at https://authorea.com/users/ 321131/articles/450580-an-evaluation-of-additives-for-mitigating-the-risk-of-viruscontaminated-feed-using-an-ice-block-challenge-model

\section{Hosted file}

Dee S, Feed mitigation figure 1.docx available at https://authorea.com/users/321131/articles/ 450580-an-evaluation-of-additives-for-mitigating-the-risk-of-virus-contaminated-feedusing-an-ice-block-challenge-model 